\title{
HYDRANTH FORMATION AND POLARITY IN TUBULARIA
}

$\mathbf{B} \mathbf{Y}$

T. H. MORGAN

The two problems of hydranth formation and of polarity in Tubularia have much in common, yet, as I shall try to show they may sometimes involve fundamentally distinct factors. Failure to distinguish the proper field of each has led, I believe, to unfortunate and unnecessary confusion.

By polarity we mean in Tubularia the formation of a hydranth on the oral end, and of a stolon on the basal end of a piece. But since in Tubularia a hydranth not infrequently develops also on the basal end of the piece, it may appear that our definition of polarity has no real significance. I do not think that this is the case, although unquestionably the problem needs further analysis.

Inasmuch as a hydranth may develop at every level, it follows that every part has the capacity to produce this organ. Why then does it not develop equally on an oral or on a basal end ? Theoretically both ends have the possibility of forming a hydranth, but there are two facts that show that the conditions are not the same on these two cut surfaces. First, when an oral and a basal end of halves of the same piece are exposed at the same level (the other ends respectively of the pieces being tied) the cut oral end develops its hydranth before the cut basal end. Second, while a stolon often develops from the basal end, and can easily be called forth, it is the rarest occurrence for a stolon to develop from the oral end, even when a hydranth is present on the basal end and a new cut is exposed near the oral end. Hence I believe we are warranted in using the term polarity in Tubularia, although the distinction between the two ends is less apparent than in other cases in which axial heteromorphosis does not occur.

Journal of Experimental Zoölogy, Vol. IIr, No. 4. 
In my last paper ${ }^{1}$ on regeneration in Tubularia I gave a number of experiments to show that when a piece is tied at its oral and its basal end, and is then cut in two in the middle, the oral cut end of the basal half develops its hydranth before the basal cut end of the oral half. I have repeated this experiment again on a much larger scale. There was one difference in the conditions of the two experiments, viz: in that in the present case the basal piece was not tied at its basal end because another experiment had shown that a basal ligature has no influence on the rate of development of the oral hydranth. The basal piece developed in practically all cases its oral hydranth before the basal hydranth of the oral half appeared. The result is, therefore, the same as when the basal end of the basal piece is ligated.

\section{THE CONDITIONS ON WHICH THE DEVELOPMENT OF THE ABORAL HYDRANTH DEPEND}

In a former paper ${ }^{2}$ I suggested that the suppression of the hydranth at the basal end of a piece, open at both ends, is due to the more rapid development of a hydranth at the oral end. If this hypothesis is correct we should expect the converse to be true and anticipate a delay in the formation of the oral hydranth if the basal hydranth could be made to develop first. This can be done by tying the oral end of a piece first, and then, as soon as the basal hydranth has begun to develop, or even after it has emerged, by cutting off the oral end of the piece below the ligature. Under these conditions I find that the development of the oral hydranth is delayed or suppressed for a time.

It would seem, therefore, that something is used up in the formation of the hydranth that is necessary for its development, and that whichever hydranth develops first uses up this something so that the other hydranth fails for the time to develop. But the conditions seem to be more complicated than this, as I pointed out, and as the following considerations will show:

\footnotetext{
I"Polarity" considered as a Phenomenon of Gradation of Materials. Jour. Exp. Zoö1, ii, I905.

${ }^{2}$ Morgan, T. H. An Attempt to Analyze the Phenomena of Polarity in Tubularia. Jour. Exp. Zoöl, i, ı904.
} 
If a long piece is cut into a number of pieces 2 to $5 \mathrm{~mm}$. in length, each will develop its oral hydranth in the same time that a long piece cut off at a corresponding level develops its hydranth. Therefore, a long piece must be capable of forming a far greater amount of the something necessary for hydranth formation than required for its oral hydranth alone. Why then does not the basal hydranth also develop?

By means of a separate experiment I found that a short piece (cut off below the hydranth) and a very long piece (cut off with its distal cut end at the same level) develop their oral hydranths in the same time. It might seem, therefore, that the effect produced involves only the immediate region near the cut surface, and the breaking down of the ridges in this region during the time of hydranth formation suggests that the active factor is the material of the ridges that is thrown into the circulation, but I have come to question whether this material is the something demanded; for as I have already pointed out, it is not obvious why the basal end might not also break down, and develop its hydranth by the use of the material thus set free, at the same time in which it develops its basal hydranth when the oral end is tied. In fact, in a certain small percentage of cases an oral and a basal hydranth develop on a piece at the same time - or very nearly so-and, more rarely, a basal hydranth may develop while the oral hydranth is delayed or suppressed. In very short pieces, less than the length of the normal primordium of the hydranth, double hydranths and partial double hydranths are of common occurrence. Therefore, I conclude that the basal hydranth fails to develop because it does not receive the stimulus necessary to start its development whatever the nature of this stimulus may be. Driesch has assumed that the stimulus calling forth the hydranth is the action of the salt water on the cut end. I tried to test this view by sticking the basal ends of long pieces into sand with only the basal part of the pieces surrounded by water. The oral ends were an inch or two above the water and surrounded by air. The air was kept saturated with moisture by covering the dish. Under these conditions the oral hydranth developed as rapidly, possibly more so, than when surrounded by water. The result does not conclusively 
show, however, that the action of the water may not be an important factor, since the surfaces above water were of course moist; yet the results do seem to show that we must be cautious in accepting Driesch's explanation as the only interpretation.

Another experiment bearing on the question under consideration is the following. The oral end of a piece was tied and then after twelve hours, before the basal hydranth had developed, the oral end was cut off below the ligature and the basal end tied distal to the region that produces the hydranth. The oral hydranth did not develop any sooner (i. e., in actual time) or at most very little sooner than it does when simply cut off. The result shows that in a tied piece the oral end does not undergo the changes preparatory to hydranth formation (as I thought probable at one time), and the more rapid development of the basal hydranth when the oral end is tied cannot be due to materials set free from the oral end that act as a stimulus for the basal development.

I must here go over again two experiments described in my last paper that appear to have a further bearing on this problem. I found that if pieces were cut off and allowed to remain with both ends open for four, six, eight or twelve hours, and then the oral ends were tied, the basal hydranths often developed as fast, or nearly as fast, as the control pieces tied at once. It might appear that changes are taking place in the aboral end of such a piece, open at both ends, that are leading to hydranth formation, and that ordinarily the changes are only retarded by the more rapid development of the oral end. That this is not the real explanation, plausible as it may seem, is shown by another experiment. If, as before, pieces are cut off and allowed to stand for several hours, then tied at the oral end as before, but at the same time several millimeters of the basal ends are cut off, these pieces produce their aboral hydranths in the same time, or nearly so, as do those whose basal end is not cut off after tying. The result shows that the acceleration of the aboral hydranth is not due to preliminary changes in that end, or at most only in a minor degree. Of course, if too much time is allowed to elapse before the oral end is tied, the control develops first, but a distinct hastening of the aboral development is nevertheless observable. I have found, for instance, that 
if the tying is delayed for twelve hours, the aboral hydranth is generally later in appearing than that of the control, but not twelve hours later, and in very favorable cases I have found them developing at the same time.

Evidently then the results cannot be ascribed to changes in the aboral end, and probably not to changes in the oral end, but must be due to something that takes place throughout the entire piece. On this "something" depends the more rapid aboral development when the oral end is tied.

Another experiment, designed to test this supposition, is important, and although I have repeated it time after time I still feel the same doubts as to the result that I spoke of in my last paper. Pieces of the same length were cut off near the oral end of the stalk. It is of much importance to have the pieces of the same length and from the same region, since the rate depends on the distance of the aboral cut-surface from the cut end. For comparison, therefore, the cut ends must be at the same level; but in addition to this the rate differs in pieces of different ages, and although I have attempted to pick out similar pieces, it is practically impossible to determine accurately the age of the piece. A small piece that has newly arisen as a bud develops more promptly than one of the same diameter that has failed to develop fully owing to crowding by the larger pieces. Pieces of the latter kind are unfavorable for comparison. With this understanding concerning a source of error the experiment may now be described. After four, six, eight and twelve hours, or at other intervals, ligatures are tied around the pieces; in some of them near the oral end, in others near the middle, and in others near the base. The development of the basal hydranth in these three kinds of pieces was then compared. The results indicate that the basal hydranths in the three kinds of pieces develop at nearly the same rate, although the shorter basal pieces are often behind the other two, as I found in previous experiments of this kind, but the delay when it occurs does not seem to be in proportion to the relative lengths of the pieces between the ligature and the basal end. In my former paper I stated that the experiment might show whether the materials set free in the circulation affect the development at the basal end, because in the longer 
piece tied near the oral end there would be more of such material shut off than in the shorter pieces tied nearer the base. This interpretation of the experiment now seems to me erroneous. There would be quantitatively (i. e., absolutely) more material in the longer piece, yet the relative amount is the same and it is the relative amount to a given volume that must act as a stimulus on the basal end. Consequently we should not anticipate quicker stimulation in one case than in another. On the other hand if the substance is notgiven off equally from the entire wall of the piece and if relatively less is given off from the basal region than from the oral region some difference in the time of basal development might follow. It may be questioned, however, whether the difference, sometimes found, is due to this rather than to some other factor. It seems to me that more emphasis should be laid on that side of the results that shows clearly there is no proportion between the length of the shorter piece and the basal development, rather than on the apparently slight difference sometimes observed in the different cases.

Before coming to closer quarters with our problem a few additional results must be briefly given:

In a few cases a series of ligatures were tied at intervals around the oral end of a piece. If the changes induced by closing the anterior end introduces a factor that accelerates the development, a number of successive ligatures might be imagined to accelerate the aboral hydranth, but no acceleration was observed.

It has been stated that a single ligature at the basal end does not hasten the oral development. Also a series of successive ligatures, several hours apart, does not accelerate the oral development.

If the development of the oral end retards the basal development, it might be supposed, conversely, that, if any changes take place at the basal end, successive removals of the basal end might accelerate the oral development; but no such result was found. This observation is in accord with other experiments that seem to show that as a rule no development, or very little, takes place for a time at the aboral end.

On the other hand, removal of short millimeter pieces from the 
oral end at intervals delays the development of the oral end but only a very little provided the intervals are not too long. For example, in one case a short piece was cut from the oral end of a long piece after five hours and another from the same piece after eight hours. The primordia appeared thirty hours after the stems had been removed from the colony, and at the same time (or so nearly so that little or no difference could be detected) in the control and in the pieces twice operated upon. In another experiment short pieces, I to 3 millimeters in length, were cut from the oral end of different pieces at different times, $i$. e., not from the same piece, successively as before, at different times. The tips of some pieces were cut off after six hours, from other pieces after nine hours, and from other pieces after twelve hours. In the control a short piece of the same length was cut off at once. It was found, when the primordia appeared that the six and the nine hour pieces developed at nearly the same rate; the twelve hour pieces were somewhat behind, but not, apparently, twelve hours behind. The controls were like the six and the nine hour pieces, but possibly a little ahead of them. Thus it appears that some effect is produced by cutting off the oral parts, out of which the hydranth develops, but not in proportion to the intervals. There was another series of operations in the same experiment. Long pieces, similar to the last ones, were removed at a much greater distance from the oral end, entirely beyond the region of polyp-formation. It was to be expected that the new oral ends would develop more slowly, because the cut surface is more basally situated. It was found, in fact, that these pieces were somewhat behind the preceding ones, but the six and the nine hour pieces developed at nearly the same rate, while the eleven hour pieces were a little retarded. There was need of a control here that was not made,so that any deduction from the results is unsafe; but it did not àppear that the six and nine hour operation had much delayed the development within the period of thirty hours.

From these last experiments it seems probable that a change takes place in the whole piece that leads up to the formation of the hydranth, as well as changes at the oral end itself. An acceleration in the formation of the hydranth results even when the oral 
end out of which the hydranth develops is removed, provided the removal is not too long deferred.

The rate of development in most of these cases had been judged by the time of the first appearance of the primordia as indicated by the end of the piece becoming red. There is allowed here some leeway, unfortunately, for personal judgment. In all cases the time of emergence of the polyps was also recorded, and in general the two results are found to coincide. The latter method is more exact in some ways, but since the polyp may not emerge until twelve to twenty-four hours after the first appearance of the primordia, it has been found better, on the whole, to judge the rate by the appearance of the primordia rather than by the emergence of the polyp, since there is a shorter time between the operation and its result, so that the effects are less likely to be complicated by other conditions.

It has been stated that in a small percentage of cases, when the pieces were left open at both ends, there was, in this species, an almost simultaneous appearance of oral and basal primordia. We must assume that pieces of this kind were also present in the experiments and these may tend to confuse the results. It is, therefore, unsafe to rely on the result of one or two pieces in a series and a larger number of cases must be recorded. In practice this source of error is difficult to control, but I do not think it has vitiated the results seriously.

When pieces are cut at intervals from the oral end there is a noticeable, and often a marked, increase in the number of basal hydranths, especially if the pieces are not too long. If very long, the time required for the basal end to produce its hydranth is so much greater than that of the oral end, that the latter is stimulated to produce a new hydranth before the aboral end can begin, hence the latter is kept in check. Very short pieces, especially those from the oral region, often produce "double hydranths," I have compared the development of such pieces with that of similar pieces producing only the oral structure, and, so far as I could make out, both developed at the same rate. In other words, the simultaneous development of the basal polyp does not seem to hold in check the oral polyp, provided both start at the same time. I 
have also observed in longer pieces that when both oral and basal primordia appear at the same time that such pieces produce their polyps as soon as do pieces that make only oral polyps. The result seems somewhat paradoxical, but goes to show, I think, that the retardation of the basal polyp is ordinarily due to its failure to receive the proper stimulus to development, rather than to any inherent lack of latent food-producing properties in the piece. The stimulus once received, however, the development can go on simultaneously with that of the oral polyp, neither suffering retardation. If this interpretation is correct it brings us a step nearer the solution of our problem.

Such is the evidence that I have been able to collect. The approach of warm weather has prevented further experimentation, since the Woods Hole Tubularia develops poorly above a certain temperature. Enough has been gathered, however, to throw some further light on the two questions of polarity and hydranth formation.

\section{CONCLUSION}

The polarity of Tubularia has something to do, I think, with the differentiation and stratification of the materials as shown by the difference in the behavior of the two cut ends of a piece. The entire stem at every level has the potency to produce hydranths and stolons, but the kind of structure produced, and the rate of appearance of the hydranths at the oral and the aboral ends shows clearly that there is something in the sequence of the layers or in the direction that is a factor in the result. This influence may be overcome by more powerful factors as when a hydranth develops from a basal end, or, as occurs more rarely, when a stolon develops from an oral end. This reversal does not, however, mean that no polarity exists. The question arises as to the nature of the postulated stratification. At one time it seemed to me not improbable that it might relate simply to the relative age of the stem at different levels. The growth in length of the stem takes place apparently just below the hydranth so that the younger parts are always the more distal parts. Hence it might appear that the age of the material gives the stratification. I soon abandoned this idea because 
Stevens and I found that when a newly formed stolon, whose growing end is its newest part, is cut off the new hydranth appears on the end originally nearer the old part; in other words on its oldest end. The new stolon shows, therefore, the same polarity as the stem; in fact, the stolon is only a continuation of the stem, and is a root only in the sense that it sticks to the substratum.

That younger pieces regenerate more quickly than older pieces was shown in an experiment in which old and young pieces from the same colony were compared. I also removed some long pieces with short lateral branches that arose near the base. The polyps were cut from the old stems and from the young branches. The young branches formed their primordia much sooner than the old stems. Each had been cut off just below the hydranths. This result shows that the old tissue of the stem becomes young again when it produces a new branch, at least so far as the material of the branch itself is involved.

The youthfulness of the stems is, therefore, an important influence in determining its rate of regeneration, but will it explain the phenomena of the polarity of the stem? I have suggested that the stratification is due to the relative amount of hydranth forming material at every level, without attempting to define more precisely what this material may be. I can now, I think, give a more satisfactory definition of this relation. The farther the level of the stem from the hydranth the greater its differentiation as stem, hence its gradation of differentiated materials and hence the longer road it must retrace to produce another structure, the hydranth. This differentiation into stem means that the latent capacity to form a hydranth can be less easily called into action. That it can be awakened, however, is shown by the regeneration of a hydranth at each level when the stem is cut; and also by the formation of a bud, which means the local awakening of a hydranth at the expense of the old differentiated material. In the new branch, therefore, we also get a quicker response in hydranth formation than in the old stem at the same level.

It may appear that the behavior of pieces of the stolon, mentioned above, contradicts my hypothesis, because the part of the piece that develops its hydranth, while nearer, it is true, to the 
old hydranth, is a new formation not connected with hydranth development at all, but with stem formation. In reality there is no contradiction here, because the tip of the stolon is a structure sui generis, and its stratification is from its tip inward. The part nearer the old stem has, therefore, less developed the stolon making qualities and more those of stem, hence the hydranth is more easily developed at this oral end where the conditions that call forth stolon formation are less active.

Loeb stated that when a ligature is tied at the oral end and an aboral hydranth develops the polarity of the whole piece has been reversed. That this is not the case was shown, convincingly, I think, by an experiment of Stevens and myself. We tied a ligature around the oral end, and then, when an aboral hydranth had developed, we cut the piece into small parts kept carefully oriented. Nearly all the small pieces produced new hydranths at the original oral ends, and the only exceptions were those from the region near the new basal polyp. In other words, the polarity has been changed only in the immediate vicinity of the new basal polyp, and the rest of the stem retains its original orientation or stratification. That its polarity might in time become changed is patent, but that it is not immediately changed by the presence of an aboral hydranth is shown by the experiment. In other words, the development of the basal polyp in a piece tied at the oral end is not due to a reversal of the entire polarity, but due to local conditions at the basal end, calling forth the development there of a hydranth, which leads to local changes in the material involved.

Loeb's theory ${ }^{1}$ that polarity as an expression of the direction of the current in the digestive tract has been fully considered by Stevens and myself in an earlier paper. Loeb's idea that the red pigment is a hydranth forming substance has also been there considered. His rejoinder to our criticisms is that it is inconsequent on our part to imply that some of the red pigment may not be hydranth forming stuff because a large part of it is thrown away but this reply fails to show in the least that the red pigment assumed

Loeb, I. Concerning Dynamic Conditions which Contribute Towards the Determination of the Morphological Polarity of Organisms. University of California Publications. Physiology, i, 1904. 
to be remaining hashad such a function. The reply of Loeb ignores álso a number of other results that we obtained that indicate that the red pigment has no such rôle, for our criticism was not based on the ejection of the red pigment alone.

I have tried not to lose sight of the possibility that the polarity may be an expression of a fundamental stereometrical arrangement of the ultimate structure of the cytoplasm. To imagine a network of this sort running through the differentiated organs might form an attractive speculation, but would be simply fanciful in the present state of our knowledge. If we imagine a stereometric network as a part of the specialized structure, we must be prepared to admit that it changes at each level as the structure changes. Therefore, it seems to me simpler to base our hypothesis of polarity on the difference in differentiation itself, and not on an imaginary polarized system associated with the living materials.

The other question, with which the present experiments are more particularly concerned, relates to the factors that hold in check the development of the aboral polyp. This may seem a trivial question in itself, yet in principle it involves some of the most obscure points in regeneration, and for this reason $I$ have studied it in detail, for it seemed to me that if we could give an answer to this question we have made a step in advance in the study of regeneration in general. While I do not pretend to have solved this problem, still the experiments permit us, I think, to push the analysis further than was possible before.

Without going over the ground already covered in the preceding account of the experiments let us attempt to scrutinize the results more closely. It has been shown that the development of the oral polyp is responsible for the retardation of the basal polyp. Conversely if a basal polyp is caused to develop first it may temporarily hold in check the formation of the oral polyp. Our problem has narrowed itself to the determination of the nature of this factor. The analysis seems to show that something must be set free in the stem that is necessary to stimulate the formation of the polyp, and also that the something is used up by the developing polyp. The stimulus is internal not external. If it were external we could not explain why the basal polyp is delayed when the oral polyp develops, 
or why it begins to develop as soon as the oral end is tied. It seems plausible that the stimulating agent is some material, set free either at the ends or by the entire wall, that is a storehouse of reserve materials. To call it hydranth forming material begs the question, and introduces an unnecessary assumption since there is no need to postulate such a substance, inasmuch as the cells of the stem in every part are themselves capable of developing into a hydranth, the more rapidly the less they are differentiated in other directions. If we assume that a stimulating substance is set free, we must then assume that it is used up in the development of the hydranth, which after all is exactly the sort of thing a food substance is expected to do.

When the oral end is tied no hydranth develops there, hence the food substance accumulating soon starts the aboral development. Once started the development continues without further need of the stimulus, because possibly in the changes that have been initiated enough material has been set free to give all that is needed for development, or possibly because a process of this kind once started can and must continue even if the stimulus that started it is removed.

This view is necessary in order to explain the simultaneous development of oral and aboral hydranths that sometimes occurs.

It may be asked whether the stimulating material is set free only near the cut ends or throughout the piece. Since the piece has potentially the power of starting a dozen or more polyps, as shown when it is cut into many pieces, I think that it is more probable that the materials are set free throughout the piece, although possibly more near the cut ends. The material must be soluble and pass into circulation, for otherwise the basal hydranth would develop irrespective of what is taking place at the oral end. The experiment of cutting off short pieces from the oral end after certa in intervals shows that the region involved must be more extensive than that occupied by the primordium of the hydranth. The greater frequency of basal hydranths under these conditions shows that initial changes have taken place at the basal end also, but that they are not very great is shown by the experiment of cutting off the basal end, and finding that the basal hydranth of a piece tied at the oral end still develops almost as fast as when left uncut. 
Why, it may be asked, does the basal hydranth begin to develop when the oral end is tied? Must we suppose that whether it develops or not (as when the oral hydranth is developing), it is still setting free materials? To answer this question we must turn to the experiments that involve tying off different lengths of basal ends. These experiments show that a longer tied-off part produces a basal hydranth only a little sooner than a shorter tied-off part. If these results are confirmed on a larger scale with more abundant and favorable material they would seem to mean that the material set free, that acts as a stimulus involves a greater part of the stem than that of the immediate hydranth forming region. That the stem has the capacity to set free much more than this has been indicated. It appears, therefore, that we are dealing here with one of those characteristic cases of organic equilibrium, not uncommon in growth phenomena and starvation periods. The stem, isolated from its feeding organ, the hydranth, slowly sets free in the fluid food materials from its reserve supply. This material is drawn upon by the first hydranth to develop, usually the oral one. The balance must be continually made good by the stem until the hydranth is finished. Should two hydranths start at the same time double the material is used up, and in order to maintain the equilibrium, double the amount must be set free by the rest of the stem. But if the amount set free is used up at the same rate by the oral hydranth, the aboral hydranth does not get the stimulus necessary to begin its development. Should it once begin, however, it proceeds without regard, or with little regard, to the amount set free by the stem, which will tend nevertheless to become greater, the greater the difference between the amount in reserve and that in the circulating fluids.

A number of experiments were made to test whether when a piece (open at both ends so that the oral end begins to develop) is tied after a time, the basal development is hastened even more than when the oral end is tied at once. This seems to be the case, but I do not think that it can be due to the materials set free at the oral end. Whatever materials are set free must be used up by the oral end as soon as it is in excess, otherwise the basal end would start. 
It seems much more probable that the basal acceleration is due to changes having been initiated in the stem that leads to the rapid formation of materials that have been taken from the fluids by the oral end. That end being suddenly closed the surplus becomes quickly sufficient to stimulate the basal polyp. But, as explained, the difficulties and uncertainties of this experiment make it undesirable to lay too much stress upon its results.

$\mathrm{My}$ analysis leads, therefore, to the following interpretation of polyp formation. The regeneration is due to changes set up in the stem resulting from the separation of the old polyp. The stimulus is largely internal, although another factor, the presence of an open end, is also essential, as shown by closing the end by means of a ligature in which case no polvp develops. ${ }^{1}$ The oral end develops first, both because it is a younger part (i.e., less differentiated stemward), and because it has the direction of differentiation for hydranth formation. Its development holds in check for a time the basal hydranths, because the hydranth that first develops uses up or may even deplete the circulating fluids of its surplus food supply. It is well known in other cases of regeneration that a growing part will grow at the expense of old parts. When the oral end is tied the food supply in the fluids of the stem soon rise to a point sufficient to start the basal development. The growth process once started is powerful enough to draw from the common body fluids or other sources sufficient material for its further development.

If tied very near the old polyp, where the cuticle is thin, an oral polyp sometimes develops behind the ligature. 